\title{
Estudos de Aula nas ações de formação de professores de Matemática: reflexões de uma aula no $6^{\circ}$ ano
}

\author{
Priscila Bernardo Martins \\ Edda Curi \\ Suzete de Souza Borelli
}

\begin{abstract}
Resumo: No presente estudo buscamos evidenciar um Estudo de Aula, que foi desenvolvido no ano de 2019 com um professor que ensina Matemática no $6^{\circ}$ ano do Ensino Fundamental em uma escola municipal da cidade de São Paulo. Trata-se de uma abordagem de natureza qualitativa de cunho interpretativo. Para a estrutura do processo de obtenção de dados recorremos à triangulação. Como resultados, observamos que a metodologia de formação Estudos de Aula possibilitou avanços nas práticas dos professores ao realizar um planejamento mais fundamentado teoricamente a partir do manuseio e estudo dos documentos e materiais curriculares da Rede Municipal de São Paulo.
\end{abstract}

Palavras-chave: Estudo de Aula. Formação de professores. Ensino de Matemática.

\section{Lesson Study in Mathematics teacher training actions: reflections from a class in the 6th year}

Priscila Bernardo Martins Doutora em Ensino de Matemática pela Universidade Cruzeiro do Sul (UNICSUL), campus Liberdade. Professor da Universidade Cidade de São Paulo, São Paulo, São Paulo, Brasil. http://orcid.org/ 0000-0001-6482-4031 $\bowtie$ priscila.bmartins8@gmail.com

Edda Curi Doutora em Educação Matemática pela Pontifica Universidade Católica de São Paulo (PUC-SP). Professora da Universidade Cruzeiro do Sul, São Paulo, São Paulo, Brasil. (D) http://orcid.org/ 0000-0001-6347-0251

凶edda.curi@gmail.com

Suzete de Souza Borelli Doutora em Ensino de Matemática pela Universidade Cruzeiro do Sul (UNICSUL), campus Liberdade. Professor da Universidade Cidade de São Paulo, São Paulo, São Paulo, Brasil. http://orcid.org/ 0000-0002-0738-8162 $\bowtie$ suzeteborelli@gmail.com

Recebido em 15/09/2020 Aceito em 03/11/2020 Publicado em 07/12/2020

\begin{abstract}
In the present study we seek to evidence a Classroom Study, which was developed in 2019 with a teacher who teaches Mathematics in the 6th year of Elementary School at a municipal school in the city of São Paulo. It is a qualitative approach of an interpretative nature. For the structure of the data collection process, we use triangulation. As a result, we observed that the training methodology Lesson Study enabled advances in teachers' practices by carrying out a more theoretically grounded planning based on the handling and study of documents and curricular materials of the Municipal Network of São Paulo.

Keywords: Lesson Study. Teacher training. Mathematics teaching.

\section{Estudios de aula en acciones de formación del clase de $6^{\circ}$ curso} profesorado de Matemática: reflexiones desde una
\end{abstract}

Resumen: En el presente estudio buscamos evidenciar un Estudio de Aula, que se desarrolló en 2019 con un docente que imparte Matemática en el sexto año de la Escuela Primaria en una escuela municipal de la ciudad de São Paulo. Es un enfoque cualitativo de carácter interpretativo. Para la estructura del proceso de recolección de datos, usamos triangulación. Como resultado, observamos que la metodología de formación Estudios de Aula posibilitó avances en las prácticas docentes al realizar una planificación más fundamentada teóricamente a partir del manejo y estudio de documentos y materiales curriculares de la Red Municipal de São Paulo.

Palabras clave: Estudio de aula. Formación de profesores. Enseñanza de las matemáticas. 


\section{Introdução}

O presente estudo decorre de um curso de extensão inserido em um Projeto de Pesquisa que foi desenvolvido em uma parceria entre a tríade Universidade Cruzeiro do Sul, Secretaria Municipal de Educação da Cidade de São Paulo e Organização das Nações Unidas para a Educação, a Ciência e a Cultura. O propósito do Projeto foi fomentar discussões e reflexões acerca da compreensão que os professores e formadores têm em relação à Matemática e o seu ensino, bem como os seus conhecimentos sobre os documentos e materiais curriculares da Rede.

As ações de formações encaminharam-se por meio da metodologia de formação denominada Estudos de Aula (Lesson Study). Trata-se de uma metodologia, originária do Japão, que se apoia em grupos colaborativos, no processo de reflexão dos professores e na pesquisa da própria prática. A metodologia se desdobra em etapas, perpassando pelo planejamento (coletivo e individual) sobre os Objetos de Conhecimento (conteúdos matemáticos), pela consecução das aulas planejadas e, por fim, pela reflexão das aulas desenvolvidas, o que pode acarretar um replanejamento de aulas futuras.

A metodologia jugyokenkyu, tradicional do Japão, teve grande repercussão em diferentes países, onde pesquisadores e professores fizeram adaptações na metodologia conforme os seus contextos e culturas, dispondo de peculiaridades em seu design, que variam em seus propósitos e processos.

Assim, nosso propósito é evidenciar um Estudo de Aula, que foi desenvolvido no ano de $2019 \mathrm{com}$ um professor que ensina Matemática no $6^{\circ}$ ano em uma escola pública Municipal da cidade de São Paulo.

\section{Pressupostos Metodológicos}

A presente pesquisa é de natureza qualitativa de cunho interpretativo. A pesquisa qualitativa permite uma abordagem diferente da investigação acadêmica, isso porque emprega concepções filosóficas, estratégias de investigações, métodos distintos de coletas de dados, análises e interpretação dos dados. Embora o processo seja parecido com o dos métodos de pesquisa quantitativa, os procedimentos qualitativos se apoiam em dados de textos e imagens, têm etapas específicas e se valem de variadas estratégias de investigação (CRESWEL, 2010). Corroboramos a ideia apresentada pelo autor de que uma pesquisa qualitativa é interpretativa, isso porque como pesquisadoras estamos especialmente envolvidas em uma experiência apoiada e intensiva com os sujeitos de pesquisa (professores).

Ao se pensar na estrutura do processo de obtenção de dados recorremos à triangulação que, de acordo com Denzin e Lincoln (2006), significa empregar múltiplas práticas metodológicas em uma única pesquisa, numa tentativa de garantir rigor, riqueza e complexidade ao estudo. Para os autores, a triangulação é um caminho seguro que reflete na compreensão em profundidade do fenômeno estudado. Desse modo, organizamos as fontes de dados em três blocos: 
1. Observação participada

2. Recursos escritos (questionários, fichas observacionais);

3. Recursos Audiovisuais (fotografia, videofilmagens, gravações em áudios).

\section{Contexto da Pesquisa}

O estudo foi idealizado e desenvolvido no curso de extensão denominado "Concepções, aportes teóricos e práticos que fundamentam o Currículo de Matemática da Cidade de São Paulo", situado no Projeto de pesquisa "Discussões Curriculares: contribuições de um grupo colaborativo para a implementação de um novo currículo de Matemática e o uso de materiais curriculares na rede pública municipal de São Paulo".

A proposição do curso, de modo geral, foi promover discussões curriculares na área de Educação Matemática, buscando contribuir para a implementação do novo currículo de Matemática da Rede Municipal de São Paulo e no aprimoramento teórico com o apoio de materiais didáticos, produzidos para subsidiar a prática pedagógica dos professores nas discussões que embasam a construção curricular e para o uso de materiais curriculares de Matemática, correspondentes ao ano de escolaridade do Ensino Fundamental.

Para cumprir com esses objetivos o curso contou com o engajamento de estudantes e egressos do programa de Pós-Graduação em Ensino de Ciências e Matemática da Universidade Cruzeiro do Sul e Assistentes Técnicos de Educação da Secretaria Municipal de Educação da cidade de São Paulo. Para a viabilização do curso, esses profissionais atuaram como formadores pesquisadores, que coordenavam os encontros com 55 professores, que ensinavam Matemática na rede municipal de São Paulo, correspondentes aos anos de escolaridade, $1^{\circ}$ ao $9^{\circ}$ ano, empregando a metodologia de formação "Estudos de Aula".

Os encontros grupais foram realizados aos sábados, com periodicidade quinzenal, nas dependências da Universidade Cruzeiro do Sul, campus Liberdade. No decorrer do Projeto, os professores e formadores-pesquisadores foram agrupados por Ciclos de Aprendizagem, em conformidade com a organização do próprio documento Currículo da Cidade - Matemática. Para este estudo, focamos no subgrupo denominado "Ciclo Interdisciplinar", que corresponde do $4^{\circ}$ ao $6^{\circ}$ ano. Esse subgrupo era composto por 23 professores que ensinavam Matemática tanto nos anos iniciais $\left(4^{\circ} \mathrm{e} 5^{\circ}\right)$ quanto nos anos finais do Ensino Fundamental ( $6^{\circ}$ ano) e três formadoras, sendo duas oriundas do Programa de PósGraduação da Universidade sede e uma da Secretaria Municipal de Educação. 


\section{As Etapas dos Estudos de Aula no Projeto de Pesquisa}

Todas as pesquisas realizadas pelo grupo CCPPM$^{1}$ priorizam as etapas de planejamento das aulas, de condução das aulas e de reflexão sobre essas aulas. Contudo, no Projeto "Discussões Curriculares: contribuições de um grupo colaborativo para a implementação de um novo currículo de Matemática e o uso de materiais curriculares na rede pública municipal de São Paulo", cenário da nossa pesquisa, sentimos a necessidade de incorporar mais 02 (duas) etapas na formação: Formação de Formadores e Divulgação de Resultados. As etapas contempladas no Projeto são evidenciadas, a seguir:

1. Formação de formadores: antes das reuniões com os professores, os formadores se reuniam, quinzenalmente, nas dependências da universidade vinculada ao Projeto, para discutir com a coordenadora responsável, as pautas de formação; os instrumentos de pesquisa; para estudar e refletir sobre as concepções que fundamentam o Currículo da Cidade; para aprofundar estudos teóricos sobre os temas que seriam tratados na formação.

2. Planejamento: os formadores conduziam as reuniões com os professores, reunidos nos ciclos em que atuavam, para selecionar uma atividade do material curricular utilizado - Cadernos da Cidade Saberes e Aprendizagens - e planejá-la coletivamente, visando antecipar as possíveis dúvidas dos estudantes, seus conhecimentos prévios, a identificação do Objetivos de Aprendizagem e Desenvolvimento, das Ideias Fundamentais e Raciocínios envolvidos, entre outros aspectos.

3. Observação das Aulas: os formadores atuavam como observadores, apoiavam-se em recursos audiovisuais e escritos, acompanhavam a aula planejada do professor que se dispôs a desenvolvê-la. 0 propósito central era o de averiguar se o planejamento elaborado servia de apoio ao professor em sua atividade de ensino e se contribuía de algum modo para a aprendizagem dos estudantes do tema matemático escolhido.

4. Reflexão das Aulas: os professores e formadores responsáveis avaliaram o percurso de organização e de desenvolvimento da aula, analisando o impacto nas aprendizagens dos estudantes e se os objetivos foram ou não alcançados, durante a realização da aula. Ademais, o grupo analisava se os procedimentos usados pelo professor estavam em conformidade com o planejado, ou seja, se houve a necessidade de fazer novos ajustes no planejamento ou se foi preciso aprofundar o conhecimento do conteúdo desenvolvido em razão dos acontecimentos da aula, dúvidas ou dificuldades ocorridas que não foram previstas de antemão.

5. Divulgação dos Resultados: essa etapa refere-se à disseminação dos resultados de variados modos como nos relatórios de pesquisa enviados para a UNESCO e para a SME, nas reuniões pedagógicas nas escolas envolvidas, nas participações em congressos nacionais e internacionais e em outros veículos de comunicação na área de Educação Matemática.

\footnotetext{
${ }^{1}$ Conhecimentos, Crenças e Práticas de professores que ensinam Matemática.
} 
A seguir, serão detalhadas e refletidas as três primeiras etapas ocorridas na turma do $6^{\circ}$ ano, foco da nossa pesquisa.

\section{O Estudo de Aula em uma turma do $6^{\circ}$ ano do Ensino Fundamental}

A seguir, serão detalhadas e refletidas as três primeiras etapas ocorridas na turma do $6^{\circ}$ ano, foco da nossa pesquisa. Antes, porém, cabe destacar a atividade escolhida e o professor que cedeu a sua aula para a fase de observação e estudo.

O Eixo Estruturante 2 "números" foi a opção da atividade 4 escolhida pelos professores do $6^{\circ}$ ano. A referida atividade está alocada na Unidade 3, Sequência 1 do Caderno de Saberes e Aprendizagens (SÃO PAULO, 2019, p. 80-82). A figura a seguir ilustra a atividade 4.

De acordo com os critérios estabelecidos, foi selecionado um professor que lecionava no $6^{\circ}$ ano. Assim, a fim de garantir o anonimato do professor envolvido, designamos a letra "P" para fazer menção a palavra professor, seguido do ano que o participante atuava, na qual apresentamos, a seguir, uma breve descrição da formação acadêmica e profissional do sujeito do nosso estudo.

O professor (P6) ministrava aulas de Matemática no $6^{\circ}$ ano do Ensino Fundamental em uma escola Municipal, localizada na região de Sapopemba, Zona Leste da cidade de São Paulo, pertencente à Diretoria Regional de Ensino de São Mateus. Possui licenciatura em Matemática desde 2009 e em Pedagogia (2013). É especialista em docência do Ensino Superior (2015) e Psicopedagogia (2014). Professor efetivo da Rede Municipal de Ensino há seis anos. Possui 10 anos de magistério. Participou de outros projetos de formação continuada na DRE São Mateus a respeito do novo Currículo de Matemática da Cidade de São Paulo.

\footnotetext{
2 Nomenclatura utilizada no Currículo da Cidade (2017)
} 


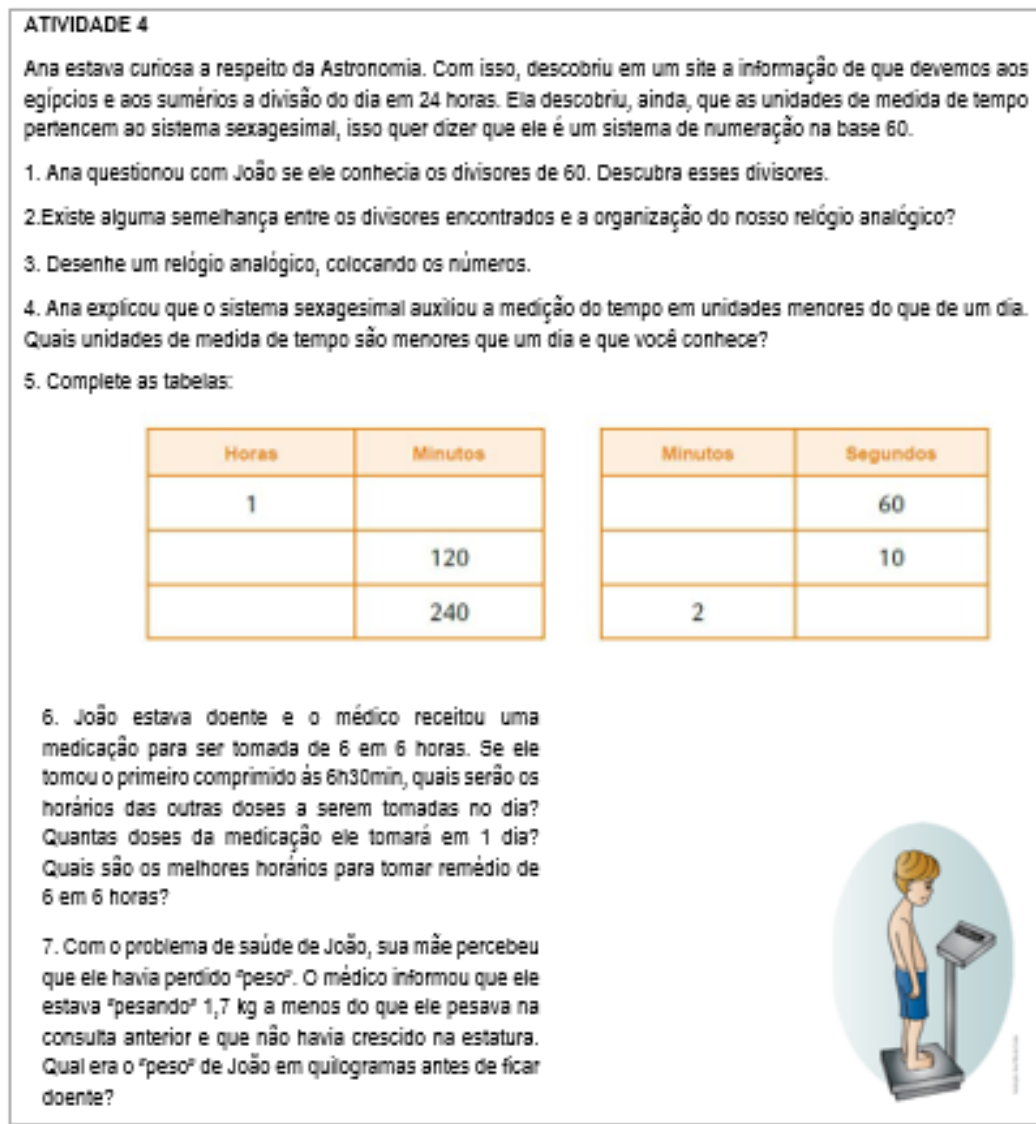

Figura 1: Atividade referente ao $6^{\circ}$ ano Fonte: Caderno da Cidade Saberes e Aprendizagens (SÃO PAULO, 2019, p. 80-82).

A atividade proposta envolve o Objetivo de Aprendizagem e Desenvolvimento "(EF06M05) Investigar relações entre números naturais, tais como "ser múltiplo de" e "ser divisor de", e reconhecer números primos e compostos e as relações entre eles.

Essa atividade envolve, em especial, relações entre múltiplos e divisores de um número e a exploração de um relógio analógico para contextualizar os divisores de 60 e o sistema sexagesimal. Dessa forma, além dos conhecimentos sobre múltiplos e divisores de um número natural, há relações entre esses conceitos que são necessárias ao desenvolvimento da atividade.

Há conceitos matemáticos envolvidos, como o de divisor de um número natural é um número natural que resulta em uma divisão exata, isto é, com resto igual a zero. O conjunto dos divisores de um número é um conjunto finito, o número 1 é divisor de todos os números naturais; um número é divisor de si mesmo.

O conceito de múltiplo de um número natural pode ser considerado como o resultado da multiplicação de um determinado número natural por outro. Nesse caso, esse resultado é múltiplo dos dois números naturais, fatores da multiplicação. Cabe destacar que o zero é múltiplo de todo número natural; todo número é múltiplo de si mesmo; o conjunto dos múltiplos de zero é um conjunto unitário, cujo único elemento é o próprio zero; o conjunto dos múltiplos de um número é infinito. 
De modo geral, o cálculo de divisores de múltiplos é priorizado no ensino em função de seu conceito e de relações entre eles. Essa discussão na formação de professores é bastante importante, pois muitas vezes o destaque para os procedimentos de cálculo de múltiplos, de divisores, de máximo divisor comum e de mínimo múltiplo comum são considerados suficientes para a apropriação dos conceitos matemáticos envolvidos.

Com relação à exploração do relógio analógico, a ideia era relacionar os divisores de 60 com os números que indicavam os minutos no relógio. Outra exploração possível era a contagem de 5 em 5 minutos a cada ponteiro do relógio relacionando à ideia de múltiplo. Mas sem essa discussão, a presença do relógio poderia não estar relacionada ao Objetivo de Desenvolvimento e Aprendizagem indicado na atividade.

\subsection{0 planejamento realizado}

0 grupo do $6^{\circ}$ ano era formado por professores e professoras e no texto será identificado por professores. Na reunião de planejamento as formadoras propuseram a leitura da atividade e a identificação do objetivo de aprendizagem. Os professores não tiveram dificuldades para elencar o objetivo. As formadoras discutiram a importância de analisar o objetivo e a atividade para identificar a parte do objetivo contemplada na atividade. Os professores logo identificaram as partes em negrito indicadas no item anterior.

No planejamento, os professores indicaram a Proporcionalidade, Representação e Ordem como ideias fundamentais da Matemática para esta atividade. Com relação aos tipos de raciocínio, os professores consideraram que o proporcional e o temporal estão incorporados na situação apresentada. Ao analisarem a atividade, os professores afirmaram que os estudantes deviam possuir conhecimentos sobre divisão, critérios de divisibilidade e reconhecimento de unidade de tempo.

As formadoras comentaram que a ideia de divisores não envolve critérios de divisibilidade e que estes podem ser construídos observando regularidades. As formadoras chamaram atenção para a nomenclatura usada na divisão, em que lugar ficam os divisores para elucidar aos professores o significado de divisor. 0 mesmo procedimento as formadoras utilizaram em relação aos múltiplos, considerados resultados de multiplicação (produto), discutindo que o resultado da multiplicação (produto) é múltiplo dos dois fatores envolvidos.

A inclusão de um relógio analógico na atividade permitiu uma reflexão dos professores que apontaram que seus alunos poderiam ter dúvidas na leitura e na interpretação dos minutos na forma como foi apresentada na atividade, uma vez que envolvendo a compreensão das unidades de tempo, não apenas relacionada a unidade hora, pois tem base 60 , mas fazer com que percebem que a unidade de tempo envolve a constituição de dia, partes do dia por exemplo 6 em 6 horas, entre outras.

Para sanar as dúvidas dos estudantes que porventura pudessem surgir, ficou combinado entre os professores que deveria ser utilizado a tabela pitagórica para ajudar na observação de regularidades dos múltiplos e nesta tabela os alunos deveria chegar até 60 , e também o uso do relógio analógico. Quando 
questionados acerca da organização da turma e o tempo estimado para o desenvolvimento da atividade planejada, chegaram a um consenso que uma aula seria suficiente, dividindo-os em duplas ou trios. A compreensão do tempo, como também o trabalho em equipe seriam dois indicativos importantes de avaliação, na opinião dos professores.

\subsection{Observação da Aula do $6^{\circ}$ ano}

No dia 12 de setembro de 2019, às $15 \mathrm{~h} 10$, ocorreu a realização da aula no $6^{\circ}$ ano, ministrada pelo professor (P6) na escola municipal.

Participaram das observações dessa aula, as formadoras pesquisadoras deste estudo. Diferentemente de uma rotina comum, em que os estudantes aguardam pelo professor na sala de aula, são eles que se direcionam até a sala da disciplina específica denominada "sala de aula ambiente", de acordo com o cronograma das aulas. No caso de nosso estudo, trata-se de uma sala ambiente de Matemática.

As formadoras destacaram que em nenhum momento, durante o planejamento, esse fato foi mencionado pelo professor (P6), pois se soubessem de antemão teriam acrescido alguns minutos no tempo previsto para duração da aula em estudo, visto que foram exatos dez minutos para que os estudantes pudessem se acomodar no ambiente.

A conversa inicial do professor (P6) com os estudantes não foi conforme o planejado para 0 desenvolvimento da atividade, pois ele dedicou os primeiros minutos para reforçar a necessidade de os estudantes terem trazidos os Termos de Consentimento assinados pelos responsáveis para participar da investigação.

As formadoras observaram que não houve qualquer tipo de orientação acerca da atividade que os estudantes desenvolveriam em sala de aula, muito menos houve a revisitação de conteúdos matemáticos que estariam presentes na atividade, nem mesmo a retomada de alguns aspectos como a construção da tabela pitagórica que já havia sido construída por parte dos alunos da turma.

As formadoras notaram que (P6) mostrava, aparentemente, insegurança e nervosismo, o que é compreensível pelo fato de suas aulas nunca terem sido acompanhadas antes, utilizando a vídeofilmagem, mesmo ciente de todas as etapas da metodologia de formação "Estudos de Aula" e o as pesquisadoras tinham um objetivo claro que era verificar se tudo o que havia sido planejado iria funcionar e quais imprevistos surgidos que possibilitariam uma melhoria do planejamento deste trabalho.

O professor convidou um estudante para fazer a leitura do item 1 da atividade: "Ana questionou com João se ele conhecia os divisores de 60. Descubra esses divisores". Após a leitura do enunciado, o professor solicitou que os estudantes consultassem a Tabela Pitagórica ${ }^{3}$ que havia sido construída

\footnotetext{
3 Trata-se de uma tabela em que são distribuídos dois eixos, um horizontal e outro vertical. Em cada um deles os números 1 a 10 são distribuídos e, em seguida, uma malha quadriculada com uma casinha é desenhada para cada
} 
anteriormente. No entanto, muitos estudantes comentaram que eles não estavam presentes no dia que foi produzida a tabela, logo, uma parte dos alunos não teriam acesso a este recurso.

O professor (P6) desconsiderou a informação dos estudantes e concedeu alguns minutos para que eles pudessem resolver 0 item 1 da atividade.

Nesse momento, destacamos alguns episódios importantes que as formadoras revelaram. 0 primeiro refere-se ao momento que uma das duplas de estudantes parecia estar confusa para validar os divisores encontrados de 60. Desse modo, a formadora-pesquisadora, inquieta com a situação vivenciada e considerando que muito tempo da aula já havia passado, chamou o professor discretamente e sugeriu que ele providenciasse calculadoras para essa validação. Então, o professor decidiu buscar as calculadoras na sala da Coordenação. Posteriormente, o professor distribuiu as calculadoras para as duplas de modo que pudessem validar os resultados.

As formadoras registraram na ficha de observação que muitos dos estudantes não sabiam como utilizar esse recurso digital, o que causou certo desconforto, pois na própria rede municipal existe um Currículo que se organiza em torno do uso das Tecnologias para a Aprendizagem e que é um recurso que grande parte das pessoas tem acesso hoje, inclusive nos celulares. Mas trouxe uma reflexão para as formadoras-pesquisadoras, não basta o recurso estar disponível, os alunos precisam manusear, e conhecer todos os recursos que a calculadora tem para poder utilizá-la adequadamente.

Verificaram ainda, em uma das duplas, que os estudantes, ao utilizar a calculadora para fazer a divisão do número 60 por 8 , identificou o número 7,5 como resultado. Desse modo, a formadorapesquisadora questionou para a dupla: Mas, isso quer dizer que o número 60 é então divisível por 8 ? Eles concordaram que sim.

Constamos haver uma dúvida inusitada e que não estava prevista no planejamento, despertando surpresa nas formadoras e no próprio professor. Um estudante questionou: Por que nos divisores de 60, apenas os números 3, 5 e 015 não são pares?

0 professor deu continuidade à aula e questionou a turma, reproduzindo o enunciado do item 2 da atividade: Existe alguma semelhança entre os divisores encontrados e a organização do nosso relógio analógico?

Alguns estudantes respondem que sim. 0 professor prosseguiu com um novo questionamento: Qual é então à similaridade? Após silêncio inicial, um dos estudantes disse: "Bom, uma hora tem 60 minutos. E um minuto tem 60 segundos".

Não convencido, o professor insistiu e explicou: Alguns dos divisores do número 60 são marcações

multiplicação entre os números dos dois eixos. Em seguida, multiplicam-se os números do eixo horizontal com os do eixo vertical, posteriormente, coloca-se o resultado na casinha correspondente da grade. Qualquer um dos eixos ou colunas pode funcionar como multiplicando ou multiplicador. Uma vez que todos os números possam ser multiplicados, a tabela pitagórica está completa. 
do relógio analógico, que é dividido em 60 partes, que são os minutos.

Após a correção oral do item 2, o professor solicitou que os estudantes representassem, no item 3 da atividade, um relógio analógico, inserindo os números necessários.

As formadoras observaram que, nessa atividade, que os estudantes puderam fazer a representação com facilidade, visto que havia um relógio analógico na parede da sala de aula.

Feitas as representações, os estudantes foram incentivados pelo professor a refletirem sobre 0 item 4 da atividade: "Ana explicou que o sistema sexagesimal auxiliou a medição do tempo em unidades menores do que um dia. Quais unidades de medida de tempo são menores que um dia e que você conhece?".

Nesse item, os estudantes apresentaram dificuldades, mesmo sabendo quais eram os múltiplos da unidade de tempo. As formadoras identificaram que alguns alunos não compreendiam o que as marcações dos números no relógio, de fato, representavam, pois identificavam apenas os algarismos que os ponteiros estavam indicando no relógio, sem estabelecer a relação entre horas e minutos e que a marcação dos números apresenta uma regularidade de 5 em 5 , representando os minutos.

As dificuldades existiam também na explicitação e nas relações dias, semana, partes de um dia, conforme observamos na realização da atividade 4 .

As formadoras observaram que não houve tempo para fazer a correção do item 4 da atividade, muito menos dar continuidade nos itens 5,6 e 7, pois o professor teria de receber a outra turma na sala ambiente.

\subsection{A Reflexão da Aula do $6^{\circ}$ ano}

No dia 5 de outubro de 2019, no período da manhã, ocorreu a reflexão sobre os episódios da aula acompanhada no $6^{\circ}$ ano. Nessa sessão, estiveram presentes os professores e formadoras do Ciclo Interdisciplinar

Seguindo a mesma dinâmica, a formadora líder recomendou que o grupo assistisse atentamente os episódios escolhidos para as nossas reflexões, que podem ser observados no Quadro 1. 
Quadro 1- Episódios do $6^{\circ}$ ano selecionados para a sessão de reflexão coletiva

\begin{tabular}{|c|c|c|}
\hline Episódios & Denominação & Descrição \\
\hline 1 & A palavra sexagesimal & $\begin{array}{l}\text { Alguns estudantes não compreenderam que a palavra } \\
\text { sexagesimal está relacionada ao sistema de numeração de } \\
\text { base } 60 \text {, e que no caso da atividade envolvia a compreensão } \\
\text { do sistema de unidade tempo }\end{array}$ \\
\hline 2 & $\begin{array}{l}\text { O uso da calculadora nas aulas } \\
\text { de Matemática }\end{array}$ & $\begin{array}{l}\text { Alguns estudantes mostraram que não sabiam utilizar este } \\
\text { recurso digital. }\end{array}$ \\
\hline 3 & "Ser divisor de" & $\begin{array}{l}\text { Os formadores que acompanhavam a aula perceberam que } \\
\text { os estudantes sabiam o que era ser divisor de um número } \\
\text { natural, no entanto, faltou uma institucionalização desse } \\
\text { conhecimento, de modo que os estudantes pudessem } \\
\text { melhorar sua linguagem e o seu registro matemático. }\end{array}$ \\
\hline 4 & $\begin{array}{l}\text { A representação parte todo } \\
\text { dentro das unidades de tempo }\end{array}$ & $\begin{array}{l}\text { Os estudantes apresentaram dificuldades em relacionar as } \\
\text { partes menores da hora com o todo, ou seja, dificuldade em } \\
\text { relacionar } 10 \text { segundos se refere a que parte do minuto. }\end{array}$ \\
\hline 5 & Gestão de tempo da sala de aula & $\begin{array}{l}\text { O professor não conseguiu finalizar as atividades propostas } \\
\text { dentro do prazo planejado. }\end{array}$ \\
\hline
\end{tabular}

Fonte: Dados da Pesquisa (2019).

No episódio 1, "A palavra sexagesimal”, o grupo sugeriu que o professor fizesse uma retomada no conceito da palavra, de modo que os estudantes pudessem compreender se tratar de uma base amplamente utilizada no sistema de medida de tempo e que esse tempo é medido na base 60 . Depois, que ele recuperasse com os estudantes o movimento da medida do tempo no relógio analógico, reforçando que a hora tem 60 minutos e o minuto têm 60 segundos.

As formadoras indicaram ainda, como sugestão, que o professor construísse uma tabela considerando as características da unidade de tempo, hora, mostrando a própria organização, sexagesimal.

As formadoras constataram no caderno dos estudantes que alguns não conseguiram identificar a semelhança do relógio analógico com os divisores de 60 , pois justificaram que alguns números não apareciam nos marcadores. Assim, as formadoras compartilharam com o grupo de professores, o protocolo, ilustrado na Figura 2, que retrata essa constatação.

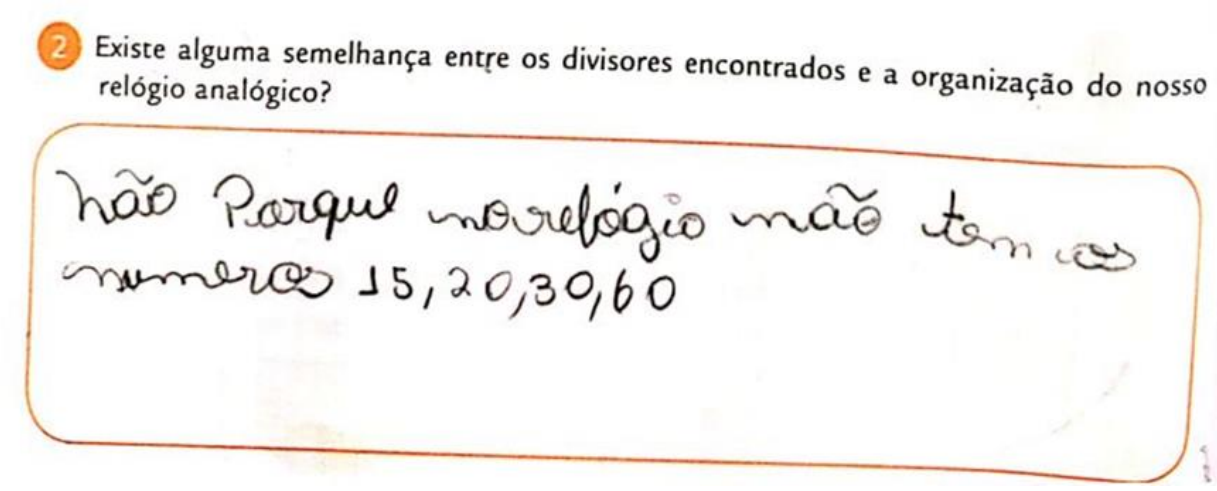

Figura 2: Protocolo do item 2 de um estudante. (Dados da pesquisa, 2019). 
A resposta do aluno, nos levou a pensar que a analogia solicitada na atividade, não é simples de ver observada, primeiro porque há dois objetos de conhecimentos envolvidos: números e grandezas e medidas - unidade de tempo. Os estudantes nesse sentido, observaram de modo distinto cada um deles, não se apoiando nos conhecimentos sobre múltiplos e divisores que havia sido organizado. Após a análise do grupo, houve a indicação dos professores do Ciclo Interdisciplinar que seria importante explorar o relógio analógico com a turma, mostrando as divisões que aparecem neste instrumento e o que se o ponteiro maior estiver parado no 3, ele indica 15 minutos, se estiver parado no 4, indica 20 minutos e assim sucessivamente.

Quanto ao episódio 2, "O uso da calculadora nas aulas de Matemática", os professores refletiram sobre a importância do seu uso nas aulas de Matemática. Assim, esses profissionais perceberam que antes de iniciar com os estudantes o uso da calculadora, é importante, primeiramente, explorar 0 funcionamento básico desse recurso, como 0 uso da tecla $=$, as operações que ela possui, a função memória, a fim de garantir que os estudantes saibam como utilizá-lo.

Quando refletiram acerca desse episódio, a fim de determinar uma relação com o uso da calculadora, os professores observaram a necessidade de ensinar os estudantes como eles descobrem que um cálculo de divisão apresenta resto diferente de zero no visor da calculadora, discutindo o surgimento do número racional e a presença da vírgula. Antes, porém, os professores sugeriram uma retomada na definição de divisores, com um pouco mais rigor matemático, de modo que os estudantes pudessem apreender que nem sempre em uma divisão de dois números naturais, o resultado é um número natural, pois isso ocorre somente quando o dividendo é múltiplo do divisor. Caso contrário, o resultado da divisão é um número racional.

Com relação ao episódio 3, "Ser divisor de", o grupo refletiu sobre a institucionalização e consolidação do conhecimento do professor, embora na visão dele os estudantes tivessem clareza sobre o que era ser divisor de um número natural, houve lacunas com relação à institucionalização desse conhecimento, pois a atividade foi desenvolvida e concluída por eles, sem exemplos e contraexemplos de outras situações, que pudessem ajudar na compreensão deste conceito, não havendo devolutivas sobre as aprendizagens dos estudantes que permitissem uma confrontação de conhecimentos que estavam sendo produzidos naquele momento.

Quanto ao episódio 4, "A representação parte-todo dentro das unidades de tempo", as formadoras-pesquisadora apresentaram os protocolos (Figura 3) dos estudantes ao grupo. Antes, porém, foi esclarecido que o tempo previsto no planejamento não foi suficiente para que o professor desenvolvesse todos os itens da atividade com a turma, todavia, os estudantes tomaram a iniciativa em dar continuidade à atividade até a sua finalização. Assim, nos protocolos analisados foram identificadas dificuldades de alguns estudantes, em fazer relações das partes menores da hora, por exemplo, eles não sabiam dizer quantas partes de um minuto 10 segundos representam. 
(5) Complete as tabelas:

\begin{tabular}{|c|c|}
\hline Horas & Minutos \\
\hline 1 & 60 \\
\hline 2 & 120 \\
\hline 4 & 240 \\
\hline
\end{tabular}

\begin{tabular}{|c|c|}
\hline Minutos & Segundos \\
\hline 1 & 60 \\
\hline 1 & 10 \\
\hline 2 & 1 \\
\hline
\end{tabular}

Figura 3: Protocolo de um estudante. (Dados da pesquisa, 2019).

(5) Complete as tabelas:

\begin{tabular}{|c|c|}
\hline Horas & Minutos \\
\hline 1 & 60 \\
\hline 2 & 120 \\
\hline 4 & 240 \\
\hline
\end{tabular}

\begin{tabular}{|c|c|}
\hline Minutos & Segundos \\
\hline 1 & 60 \\
\hline 0 & 10 \\
\hline 2 & 120 \\
\hline
\end{tabular}

Figura 4: Protocolo de um estudante. (Dados da pesquisa, 2019).

5. Complete as tabelas:

\begin{tabular}{|c|c|}
\hline Horas & Minutos \\
\hline 1 & 60 \\
\hline 2 & 0 \\
\hline 4 & 120 \\
\hline 4 & 240 \\
\hline
\end{tabular}

\begin{tabular}{|c|c|}
\hline \multicolumn{1}{|l|}{ Minutos } & Segundos \\
\hline 1 & 60 \\
\hline 0 & 0 \\
\hline 20 & 10 \\
\hline
\end{tabular}

Figura 5: Protocolo de um estudante. (Dados da pesquisa, 2019). 
(5) Complete as tabelas:

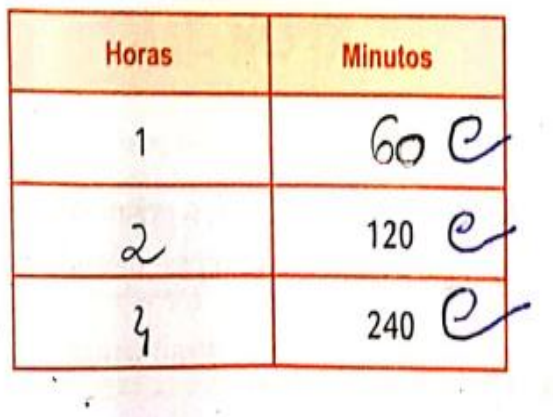

\begin{tabular}{|c|c|}
\hline Minutos & Segundos \\
\hline$\perp$ & 60 \\
\hline 0 & 10 \\
\hline 2 & $\perp 20$ \\
\hline
\end{tabular}

Figura 6: Protocolo de um estudante. (Dados da pesquisa, 2019).

O grupo constatou que os estudantes não sabiam que a ideia era representar em um número racional sob a forma fracionária, ou seja, que eles deveriam perceber que 10 segundos representam $\frac{1}{6} \mathrm{de}$ um minuto. Para eles, era mais fácil dizer que 120 minutos significa 2 horas ou 60 segundos significa 1 minuto, ou vice-versa.

Isto mostra que não é fácil a compreensão da unidade de tempo, ela está organizada em uma base diferente da decimal e que a relação de múltiplos é muito mais fácil e tranquila do que a relação de submúltiplos, principalmente se este número representar uma parte menor que uma hora, que um minuto ou um segundo.

Como sugestões, o grupo optou pela construção de representações da relação parte-todo das unidades de tempo a partir de uma tabela.

Nas discussões realizadas no episódio 5 , "Gestão de tempo da sala de aula", as formadoras destacaram sobre a relevância da conversa inicial com os estudantes, a fim de orientá-los a respeito dos objetivos da atividade, dos conceitos a serem formados e procedimentos a serem trabalhados e da identificação cuidadosa dos conhecimentos prévios dos estudantes.

\section{Algumas reflexões}

A partir dos dados da pesquisa, observamos indícios de crença do professor (P6) de que os estudantes sabem utilizar recursos digitais ou recursos de apoio instintivamente, sem necessidade de ensinar. Atualmente, os recursos digitais também são considerados como recursos manipuláveis.

Os dados da pesquisa sugerem que a proposta de que o professor fizesse uso da calculadora com seus estudantes, para validar os resultados, acabou provocando um afastamento do objetivo de aprendizagem da atividade, pois muitos estudantes nem sequer sabiam como utilizar esse recurso digital e ficaram mais focado na aprendizagem do uso da calculadora do que nos objetivos da atividade proposta.

Notamos, inclusive, a partir dos registros de campo, que a Tabela Pitagórica e o Relógio Analógico 
foram outros recursos empregados pelo professor (P6), que evidenciaram a sua crença de que os estudantes se apropriam desses recursos sem a necessidade de ensino, pois não havia trabalhado com a tabela Pitagórica com a turma toda, confiando plenamente que os estudantes saberiam utilizá-la sem dificuldades.

Com relação ao relógio analógico, antes de iniciar a atividade, o professor poderia tê-lo explorado, isto favorecia uma melhor compreensão das relações entre horas, minutos e segundos contribuindo para uma melhor compreensão da atividade por parte dos estudantes.

Compreendemos que o uso desse e outros recursos podem tornar a aula mais criativa, permitindo que os estudantes tenham um interesse maior pelo objeto matemático abordado, permitindo a construção de conceitos de maneira mais significativa. Porém, é primordial que o professor faça a mediação desse processo, contribuindo para que os estudantes aprendam a utilizar esses recursos em situações didáticas diversas, construindo e ressignificando conhecimentos a partir de experimentações.

Os dados indicam que nem mesmo um planejamento impecável garante a antecipação de todos os imprevistos, que é uma característica muito presente em sala de aula. No planejamento, o professor (P6) não declarou para o grupo que a escola dispunha de uma sala ambiente para as aulas de Matemática, impossibilitando que fosse previsto maior tempo para a realização da atividade proposta, como também para indicar outros recursos de apoio que uma sala ambiente deve dispor para favorecer o desenvolvimento da criatividade dos estudantes e dos professores.

A sala ambiente que não foi mencionada no planejamento e a previsão de tempo para a realização da atividade pelo grupo de professores foram imprevistos que ocorram na turma do $6^{\circ}$ ano. Estes elementos acabaram comprometendo a finalização e a sistematização da atividade como deveria, sem feedback acerca das aprendizagens dos estudantes, tampouco sem a retomada de conteúdos importantes que foram trabalhados, não havendo apropriação dos conceitos abordados na atividade.

$\mathrm{Na}$ etapa de reflexão, a gestão da sala de aula foi uma das pautas de discussões do $6^{\circ}$ ano. Nessa reunião, o professor espontaneamente admitiu para as formadoras e para o grupo de professores que a gestão da sala de aula foi realmente um dos maiores desafios enfrentados por ele.

Contudo, é importante destacar que apesar de todos os desafios que foram enfrentados, o professor mostrou que a formação trouxe muitos ganhos para a sua profissionalização, entre elas indicamos um olhar mais atento para os conhecimentos prévios dos estudantes, possibilitando um melhor direcionamento na organização da atividade proposta. Outro aspecto bastante relevante apontado por ele, foi o conhecimento específico para ensinar (Ball, Thames e Phelps, 2008), ou seja, ele percebeu que não basta conhecer o conteúdo matemático, é preciso aliar este conhecimento com a escolha das estratégias didáticas e metodológicas que serão levadas para a sala de aula.

Autores como Nery (2007), chamam a atenção para o planejamento, pois é a fonte de todo 0 trabalho que ocorre na sala de aula. Para a autora, há uma questão primordial a ser enfrentada no trabalho 
do professor em sala de aula: o tempo, que geralmente é escasso e requer a necessidade de aperfeiçoálo didaticamente.

Segundo Nery (2007), o tempo deve ser organizado de modo flexível, permitindo a retomada e aprofundamento dos Objetos de Conhecimento. Além disso, diferenciar a forma de organizar o trabalho do professor pode gerar oportunidades múltiplas para cada estudante, o que indica um ganho exponencial para a sua própria formação.

Concordamos com os autores da necessidade de organizar o tempo, contudo, corroboramos também com Boavida e Ponte (2002), que a colaboração é permeada pela imprevisibilidade, uma vez que é um processo dinâmico, criativo, modificável. Muitas vezes, torna-se necessário refletir e reajustar a rota. Esses reajustamentos, por sua vez, têm de ser renegociados durante o desenvolvimento do Projeto de Pesquisa.

\section{Considerações Finais}

A metodologia de formação Estudos de Aula possibilitou avanços nas práticas dos professores ao realizar um planejamento mais fundamentado teoricamente a partir do manuseio e estudo dos documentos e materiais curriculares da Rede.

Na etapa de observação da aula planejada foram reveladas as crenças dos professores, especialmente com relação ao uso de materiais manipulativos em sala de aula; lacunas nos conhecimentos de conteúdos dos professores para ensinar Matemática, especialmente ao que se referia aos objetos matemáticos que estavam subtendidos nas propostas. Na etapa de reflexão, muitos desses fatores foram refletidos, aprofundados e ressignificados para os professores, o que permitiu mudanças nas práticas de sala.

Ao planejar as atividades no coletivo, com seus pares, o grupo construiu conhecimentos sobre a Matemática e seu ensino, dos currículos e dos estudantes e passaram a reconhecer as potencialidades dos documentos e materiais curriculares, assim assumiram a postura de protagonistas nas decisões de desenvolvimento curricular.

Os dados da pesquisa revelam que a metodologia de Estudos de Aula, ao viabilizar a discussão coletiva das necessidades reais dos estudantes nas situações de ensino, possibilitou mudanças nas práticas dos professores e, consequentemente, melhorias nas aprendizagens matemáticas dos estudantes.

Consideramos que um dos aspectos que contribuiu para as aprendizagens dos professores e estudantes foi a compreensão que esses professores adquiriram no decorrer das formações a respeito dos documentos e materiais curriculares empregados na Rede Municipal e no Projeto de Pesquisa. A partir do momento que esses professores tiveram clareza de quais eram os Objetivos de Aprendizagem e Desenvolvimento, as Ideias Fundamentais da Matemática e os Tipos de Raciocínios envolvidos nas 
atividades, eles passaram a identificar os conhecimentos matemáticos necessários que os estudantes deveriam ter para o desenvolvimento das propostas de ensino, o que encaminhou as aprendizagens dos estudantes e o desenvolvimento profissional do grupo de professores.

\section{Referências}

BALL, D. L.; THAMES, M. H.; PHELPS, G. Content knowledge for teaching: what makes it special? Journal of Teacher Education, v. 59, n. 5, p. 389-407, 2008.

BOAVIDA, A. M.; PONTE, J. P. Investigação colaborativa: Potencialidades e problemas. In GTI (Ed.). Reflectir e investigar sobre a prática profissional (p. 43- 55). Lisboa: APM, 2002.

BORELLI, S. S. Estudos de Aula na formação de professores de Matemática em turmas do $7^{\circ}$ ano do Ensino Fundamental que ensinam números inteiros. 2019. 247f. Tese (Doutorado em Ensino de Ciências e Matemática) — Universidade Cruzeiro do Sul. São Paulo.

CURI, E; MARTINS, P. B. Contribuições e desafios de um projeto de pesquisa que envolve grupos colaborativos e a metodologia Lesson Study. Revista Brasileira de Ensino de Ciências e Tecnologia: REBCT, Ponta Grossa, v. 11, n. 2, p. 268-287, 2018.

CURI, E. Reflexões sobre um Projeto de Pesquisa que envolve grupos colaborativos e a metodologia Lesson Study. In: CURI, E.; NASCIMENTO, J. C. P.; VECE, J. P. (org.). Grupos Colaborativos e Lesson Study: contribuições para a melhoria do ensino de matemática e desenvolvimento profissional de professores. São Paulo: Alexa Cultural, 2018. p. 17-33.

CURI, E. (comp.). O ENSINO DE MATEMÁTICA EM QUESTÃO: apontamentos para discussão e implementação do currículo da cidade. 2019. Disponível em: http://portal.sme.prefeitura.sp.gov.br/Portals/1/Files/53083.pdf?fbclid=IwAR1AU3hi_al_1h1Sr1yE BvA6vcA9sxwcVBnFLRbia53dk1FWUYntXLjzmOI. Acesso em: 10 out. 2019.

CURI, E. (comp.). A metodologia Estudos de Aula na formação de professores que ensinam Matemática: aspectos metodológicos, potencialidades e desafios. 2020.Disponível em: http://portal.sme.prefeitura.sp.gov.br/Portals/1/Files/53083.pdf?fbclid=IwAR1AU3hi_al_1h1Sr1yE BvA6vcA9sxwcVBnFLRbia53dk1FWUYntXLjzmOI. Acesso em: 12 março. 2020.

MARTINS, P.B. 2020. Potencialidades dos estudos de aula para a formação continuada de um grupo de professores que ensinam matemática na rede municipal de São Paulo no contexto de uma pesquisa envolvendo implementação curricular. 251f. Tese (Doutorado em Ensino de Ciências e Matemática) — Universidade Cruzeiro do Sul. São Paulo.

MENEZES, L.; PONTE, J. P. Da reflexão à investigação: percursos de desenvolvimento profissional de professores do $1 .{ }^{\circ}$ ciclo na área de matemática. Quadrante, Lisboa, Portugal, v. 15, n.1-2, p. 3-32, 2006.

NERY, A. Modalidades organizativas do trabalho pedagógico: uma possibilidade. In: BRASIL. Ministério da Educação. Ensino Fundamental de nove anos: orientações para a inclusão das crianças de seis anos de idade. Brasília: MEC, 2007.

SÃO PAULO (Município). Secretaria Municipal de Educação. Coordenadoria Pedagógica. Currículo da Cidade: Ensino Fundamental: Matemática. São Paulo: SME/ COPED, 2017. 
SÃO PAULO (Município). Secretaria Municipal de Educação. Coordenadoria Pedagógica. Orientações Didáticas do Currículo da Cidade: Matemática: volume 1. São Paulo: SME/COPED, 2018.

SÃO PAULO (Município). Secretaria Municipal de Educação. Coordenadoria Pedagógica. Orientações Didáticas do Currículo da Cidade: Matemática: volume 2. São Paulo: SME/COPED, 2018.

SÃO PAULO (Município). Secretaria Municipal de Educação. Coordenadoria Pedagógica. Currículo da Cidade: Ensino Fundamental: Matemática. São Paulo: SME/ COPED, 2017.

SÃO PAULO (Município). Secretaria Municipal de Educação. Coordenadoria Pedagógica. Orientações Didáticas do Currículo da Cidade: Matemática: volume 1. São Paulo: SME/COPED, 2018.

SÃO PAULO (Município). Secretaria Municipal de Educação. Coordenadoria Pedagógica. Caderno da Cidade Saberes e Aprendizagens: Matemática: volume único. versão estudante. São Paulo: SME/COPED, 2019.

SÃO PAULO (Município). Secretaria Municipal de Educação. Coordenadoria Pedagógica. Caderno da Cidade Saberes e Aprendizagens: Matemática: volume único. versão professor. São Paulo: SME/COPED, 2019. 